\title{
Economic Theory to Visualize the Value of Design: A Case Study on The User's Perception of Value
}

\author{
Maria Cristina Morejon Alava \\ Savannah College of Art and Design (SCAD), Savannah, GA, USA
}

\begin{abstract}
Following John Heskett (2017), this paper posits that economic value cannot be defined without transcending and acknowledging the user as its source. His research presents economic theory linked to the value creation process applicable to study the value of design. This paper proposes that economic theory can be used to evaluate the impact of design when understanding and interpreting the subjective perception of value. A plan for a cross-sectional case study is explained to collect and analyze qualitative data in two stages with a means-end theory approach. This research aims to: (1) Understand the user's perception of value, (2) Evaluate the impact of design by reflecting on economic theory and (3) Analyze the relationship between design and economics regarding economic value to contribute to the business of design. It may lead to the development of an evaluation model to guide organizations towards the creation or improvement of products, services or systems with a better understanding and a more measured perception of how users perceive value for decision-making.
\end{abstract}

Keywords: Design, Economics, Economic value, Perception of value

\section{Introduction}

The design management field faces the constant challenge of emphasizing the value of design as a strategic business resource and not a decorative tool. Designing should be a vital instrument to be sustainable in business, it is essential to demonstrate its worth. John Heskett (2017) explains the economic theory as a way to examine the value of design. In the context of the following study, Heskett (2017) defines design as a strategic and planning instrument and expresses that this view is not yet common. Design, as an expression of our perceptions, is connected with the business context by using economic concepts that shape the business world. For this approach, value is a mediator between design and economics that shows their intemal relation (Heskett, 2017).

The study of the value of design and its strategic role is relevant due to the rapid changes in technological developments and innovations that are causing uncertainty and complexity for businesses and industries (Heskett, 2017). These technological changes are part of the Fourth Industrial Revolution as introduced by Schwab (2017):

It is characterized by a range of new technologies that are fusing the physical, digital and biological worlds, impacting all disciplines, economies and industries, and even challenging ideas about what it means to be human (World Economic Forum).

In the business context, the expectations of customers and the way organizations functions are shifting (Schwab, 2017). Given this technological reality, there is a need to understand the disruption and think stra tegically about the shape that future organizations are taking (Schwab, 
2017). It is significant that professionals in the field who are aspiring to strategic roles for understanding the economic arguments behind the value of design in a business context (Heskett, 2017) with the current technological situation (Schwab, 2017).

\section{Literature Review}

John Heskett's approach to value creation was the inspiration for the structure of this research. $\mathrm{He}$ reconciles economics with design and addresses their confrontation by using value as the mediator. The reason why Heskett is being used as a primary reference and point of start in this paper is due to the strong connection he has established between these fields. The value creation process he mentioned touches on aspects that are relevant to the case study from the areas of economics and design explored in the literature.

\subsection{Economics}

To connect economics to design, Heskett (2017) refers to the following definitions:

Economics is concerned with explaining the production, distribution, and consumption of wealth. Design is the human capacity for shaping and making in ways that satisfy our material needs and create meaning - in doing so; it establishes sources of wealth (Heskett, 2017, pg. 45).

To a certain extent, it is in agreement with Von Mises (1996) who defines economics as "the science of human action". It can be said that Von Mises considers economics a study of human's behavior and the meaning such as their goods and their wealth, not wealth itself. By understanding the actions humans take concerning wealth as an example, the perspectives are linked. Explanations can arise regarding the consumption of wealth. Becker (2013) discusses how the definition given to economics in terms of material goods does not fully encompass what an economist does. He outlines how economics refers to the approach and not to the subject matter, which intends to maximize utility (Becker, 2013). Heskett's (2017) can link economics and design by explaining the meaning of what the subject does.

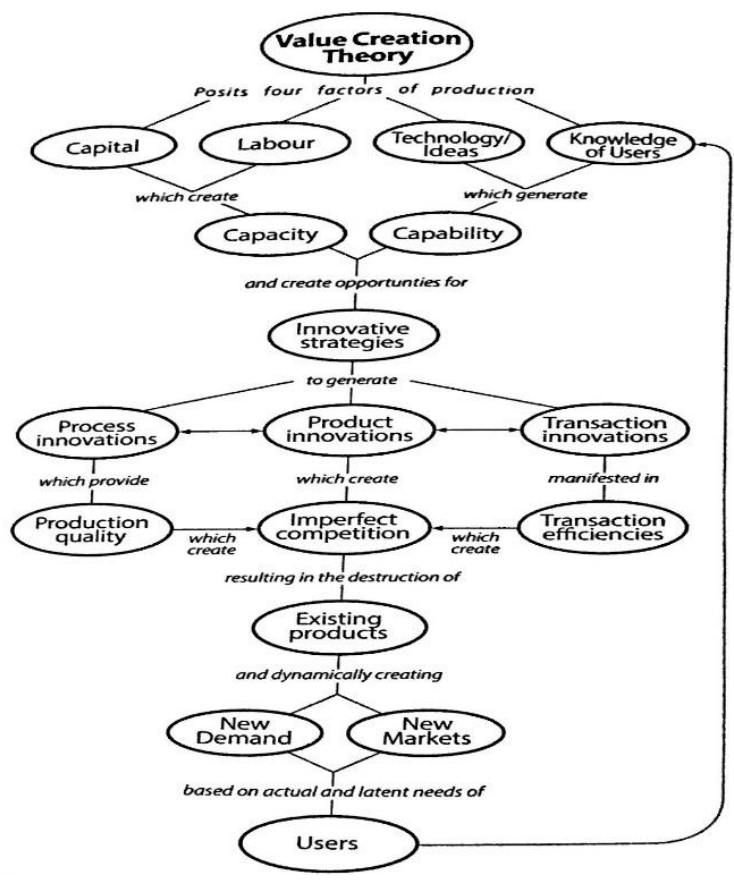

Figure 1: Value Creation Theory.

Source: Heskett (2017, p. 151) 
Heskett's (2017) develops a value creation theory (Fig.1) building on the following economic theories: Neo-classical, Austrian, New Growth and Institutional to explain their contribution to the value creation process. The value creation process occurs by connecting both contexts: the context of production and the context of use (Heskett, 2017). In this model explaining value creation, Heskett (2017) contributes by including knowledge of users as an additional factor of production with capital, labor and technology/ideas (Fig. 1). This explanation is done assuming that the decisions of production are more and more driven by considering the user's perspective and intending to make the innovation adaptable. The outcome of the model is the creation of new demand and new markets that address the existing needs of the users.

Schumpeter contributed to the New Growth Theory by explaining that the increase in growth occurred given to the interaction between technology and firm competition (Heskett, 2017). Schumpeter described it as "creative destruction," which refers to the outcome of innovation (Heskett, 2017). The value creation model intends to go beyond the New Growth Theory since Heskett (2017) criticizes it for not identifying the factor that destroys the existing elements in the market. However, innovation itself offers designers the opportunity to engage the users into making subjective interpretations to reflect on themselves (Heskett, 2017). This study aims to target the alignment between the context of use and the context of production by considering the knowledge of the users as well as the opportunity to innovate.
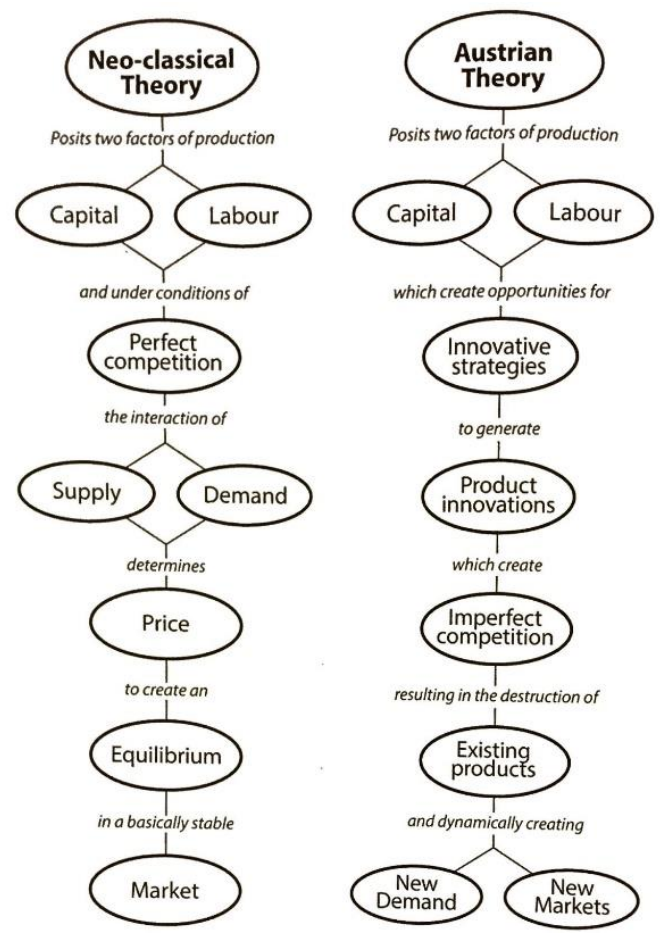

Figure 2. Neo-classical Economics and Austrian Theory (Heskett, 2017, p. 78)

As part of Heskett's (2017) construction of the value creation theory, he compares two main theories (Fig. 2). According to Carl Menger, the founder of Austrian economics, the consumer attributes value to the good, based on the expected satisfaction of their wants (Heskett, 2017; Menger, 1871). It is relevant to consider that the Neo-classical perspective functions under the assumption that consumers are rational. This assumption means that consumer preferences are consistently given a decision-making process that maximizes utility and has accurate cost calculations (Heskett, 2017). Additionally, the Neo-classical view considers individual preferences or tastes as a given which is why, according to Heskett, it does not take design into account. The way the Austrian perspective questions and challenges the Neo-classical 
perspective regarding the rationality and subjectivity of the users is relevant to this research by considering the behavioral components of the user's perception of value.

This section primarily intends to extract and summarize from economics multiple theories relevant to how value is created to further on position design as a potential producer of economic value. It is meant to obtain a general understanding of the mentioned approach to the value creation process used by Heskett (2017). The contrast between Neo-classical Theory and the Austrian Theory is relevant due to the behavioral aspect of users. Heskett (2008) emphasizes the importance of understanding economic theory since it shapes the business context. The objective of this research is to recognize economic theories and use Heskett's work as a framework into what is relevant within the economic theory to relate it to value creation in design.

\subsection{Value}

Adam Smith (1970) introduces the terms value-in-use as the utility and value in exchange as the price or the purchasing power. He explained that value in exchange is more important than value-in-use from an economic point of view (Smith, 1970). Weiser's point of view (1891) from the Austrian theory establishes that value-in-use is individual and when seen collectively, the value in exchange (price) is recognized. Considering the ways value can be applied, it is essential to differentiate between adding and creating value. Adding value occurs once the decisions have been made already while creating value allows being part of the strategic decision-making processes (Heskett, 2017).

\section{Economic Value}

The word value is often interpreted as a monetary term. Even though a financial type of value is a fundamental measurement for any business activity, by focusing only on the economic value, we fail to notice the ways by which profitability is achieved and maintained (Heskett, 2017). For this reason, Heskett (2017) not only presents the economic value that design can create but also intends to go beyond into the subjective value of the users. The design process includes the decision-making regarding the quality and value of the product (Walsh et al., 1988), which have the potential to create a better understanding of the user's perception.

Lockwood (2007) recognized the need to find ways to measure the value of design in business contexts. He presents a framework for its measurement based on ten categories relevant to design management (Lockwood, 2007). The present study has the potential to be applicable in the type of increase of customer satisfaction (Lockwood, 2007) through behavioral insights of the user's perception of value. Cooper, R., Bruce, M., Wootton, A., Hands, D., and Daly, L. (2003) mention: 'good design addresses stakeholders needs, feeds innovation and contributes to consumer satisfaction and increased sales' (p. 367). This definition of a successful design process tackles these areas, which this study intends to relate.

The decision-making processes within the design can impact an organization's profitability by increasing customer satisfaction through a better understanding of the user's perceived value. ' In the end, it all comes down to people and values. We need to shape a future that works for all of us by putting people first and empowering them' (Schwab, 2017, p. 41). He agrees with Heskett that the value of design is financial as well as non-financial. Value can be represented as quantifiable satisfaction, but it is not only that; the personal meaning it has to each customer is relevant as well (Heskett, 2017). Foglieni (2018) adds to this by saying: 'From an etymological point of view, the term value refers both to finding a numerical expression for and estimating the worth of ( $p .74)$. Considering the economic value but understanding that there is more value behind it is fundamental for this research.

\section{Customer value}

Woodruff (1997) provides an understanding of customer value and what does it mean to customervalue delivery. He emphasizes on differing between creating value for the organization 
and what the product/service means to the customer. An alternative interpretation of customer value, not used in this study is the value as in low price (Sánchez-Fernández, R., \& IniestaBonillo, M. Á, 2006). This study will take forward the definition of customer value provided by Woodruff (1997):

Customer value is a customer's perceived preference for an evaluation of those product attributes, attribute performances and consequences arising from using which facilitates (or block) achieving the customer's goals and purposes in use situations (Woodruff, 1997, p.142: (Sánchez-Fernández, R., \& Iniesta-Bonillo, M. Á, 2006)).

Based on this definition, a link exists between customer value and the user's perception and preferences. This study will necessarily translate the user's perception into what the customer values to justify the economic value. This process will create awareness of where is the value? As Boztepe (2003) mentions, in order to create value for the user there is a need to understand: '(1) what constitutes value, (2) the role of design in creation of value for users and (3) the methods and tools that facilitate value creation' (p. 1). This research will primarily target (1) and (2) with the potential to more than facilitate, evaluate the value creation process. This section of the literature is intended to provide a context for what value means in this study in regards to the question of what is the worth of design.

\subsection{Design and the User}

Heskett (2017) relates to the design and the user by saying: 'The role of design is to make innovation acceptable to users within the producing organization and at various levels in targeted markets' (p. 168). He considers that design has multiple interpretations and subjective meanings. He recognizes the design's significance across economic activities and considers it what distinguishes us as human beings. Simon (1996) seems to agree by mentioning that: 'design like science is a tool for understanding as well as for acting' (p. 164). Both interpretations of design highlight the particular meaning or perspective of the user. Heskett (2017) utilizes the term user in the context of design while the consumer in the context of business.

The rational maximizing model shows what customers should choose and not what they choose (Thaler, 1980). The purpose behind considering the behavioral aspects of the economic transactions and the perception of the users is to challenge the assumption of the Neo-classical view that people make rational decisions and justify the different perceptions of the users. To do that, decision-making processes from both contexts the users and production will be considered. Foglieni (2018) recognizes decision making an evaluation process. Heskett (2017) relates to design and economics as both involving changes, both aiming to acquire a more satisfactory state than the existing ones. That shift to achieve a different outcome relates to decision-making. Schwab (2017) refers to the decision processes being made:

Today's decision-makers are too often trapped in traditional, linear thinking or too absorbed by the multiple crises demanding their attention to think strategically about the forces of disruption and innovation shaping our future (Schwab, 2017, p. 41).

The design process includes the decision-making regarding the quality and value of the product (Walsh et al., 1988), which has the potential to create a better understanding of the user's perception. Lockwood (2007) recognized the need to find ways to measure the value of design in business contexts. He presents a framework for its measurement based on ten categories relevant to design management (Lockwood, 2007). This study aims to impact the category of increase of customer satisfaction (Lockwood, 2007) through behavioral insights of the user's perception of value. Cooper et al. (2003) mention: 'good design addres ses stakeholders needs, feeds innovation and contributes to consumer satisfaction and increased sales' (p. 367). This definition of a successful design process tackles areas, which this study intends to relate. The 
decision-making processes within the design can impact an organization's profitability by increasing customer satisfaction through a better understanding of the user's perceived value.

There is an opportunity to understand the user's perception of value from a design perspective and use it as a competitive advantage to overcome the changes that organizations are facing given the current technological changes. It is relevant to do it through economic theory since it is sustainable in a business context. This section is meant to understand the way design relates to and creates economic value.

According to Heskett (2008), that is what integrates design into a business. The literature covers the three areas, economics, value creation and design for the user following Heskett's structure to understand the relationship between them. The potential op portunities this literature presents are to acknowledge economic value but by presenting a better understanding of its source, which is its users. The theory and methodology behind this study are intended to understand the user's perception in depth and to connect it to its context.

The primary research will be conducted in the aims of developing an evaluation within the value creation process done by design. In the end, this research aims to be a particular example allowing visualizing the value of design in the case study within a specific context. The contribution of this piece of work aims to be the addition of an evaluation process for design and economic value. Overall, it will highlight the value of design within a business context.

\section{Research Methodology}

This section focuses on the potential methodology of the study. The main research question is: How can economic theory be used to evaluate the impact of design when understanding and interpreting the perception of value? The sub-questions are: How is the value of design considered in the design management field and how can it be evaluated? What are the perspectives of value in the different economic theories? How do the user and producer perceive value? How does behavioral economics relate to the perception of value?

\subsection{Sample}

The sample consists of multiple and diverse stakeholders from a specific industry (larger scale) or organization (smaller size). The ideal sample encompasses multiple and diverse stakeholders that systematically interact with each other. It will allow a different perspective of producers and users and a complex value creation process.

In any case, the presence of multiple interactions between users and producers in any industry will work for the planned methodology. This study will have participants from the two contexts, producers and users. The participants will be selected by using cluster sampling from probability sampling. The population will be clustered into separate groups (by age, the purpose of travel, domestic or international, type of organization, size of the organization). There could be a further opportunity to make categorizations based on the analysis of the insights. The responses will be kept anonymous, and the primary research will follow protocols for consent on recording the interview and taking pictures.

\subsection{Case Study}

The data will be collected through a cross-sectional case study. The objective is to understand and interpret the perceptions of value from the overall stakeholders. To do that, this case study will be divided into two stages. The first stage is intended to obtain a general understanding of the systems and the context of producers and users. The second stage is aimed at understanding and interpreting the perceptions of the value of the stakeholders. The first stage sets the framework of the study to start the second stage and focus on value. 
Table 1: Case study plan

\begin{tabular}{|c|c|c|c|}
\hline Stage & & Data Collection & Data Analysis \\
\hline (1) General & $\begin{array}{l}\text { Observatio } \\
\text { ns } \\
\\
\text { Questionna } \\
\text { ires }\end{array}$ & $\begin{array}{l}\text { Observe different settings of } \\
\text { stakeholders and the interactions } \\
\text { between producers and users. } \\
\text { Understand the overall system. } \\
\text { Understand the contexts and roles of } \\
\text { producers and users, in a more } \\
\text { specific way. }\end{array}$ & $\begin{array}{l}\text { (1) Flow } \\
\text { diagrams. } \\
\text { (2) Systems } \\
\text { mapping. } \\
\text { (3) Matrices } \\
\text { along with } \\
\text { secondary } \\
\text { research. }\end{array}$ \\
\hline (2) Value & $\begin{array}{l}\text { Semi- } \\
\text { structured } \\
\text { interviews } \\
\text { and } \\
\text { laddering }\end{array}$ & $\begin{array}{l}\text { Utilize means-ends theory as the } \\
\text { approach and the Boztepe's (2003) } \\
\text { framework that considers the context. }\end{array}$ & $\begin{array}{l}\text { (1) Transcribe } \\
\text { and re-read the } \\
\text { interviews. } \\
\text { (2) Develop } \\
\text { descriptive } \\
\text { coding to } \\
\text { summarize. } \\
\text { (3) Develop } \\
\text { process and } \\
\text { dramaturgical } \\
\text { coding. } \\
\text { (4) Develop } \\
\text { themes and } \\
\text { matrices. } \\
\text { (5) Potential } \\
\text { opportunity for } \\
\text { journey } \\
\text { mapping by } \\
\text { categorization } \\
\text { and elements of } \\
\text { value. }\end{array}$ \\
\hline
\end{tabular}

Stage 1

This stage consists of collecting general qualitative data through observations and questionnaires in both contexts (producers and users). The objective of this first stage is to obtain a fundamental insight into the system and the stakeholders to develop questions for Stage 2. The data collected from the observations will be complemented with secondary research to allow an understanding of the history of the industry and its key variables. The insights from the observations will be analyzed by the development of flow diagrams and systems maps to visualize the process and interactions of the stakeholders. From both methods, key insights will be placed into matrices along with theory from secondary research. Hypotheses will be elaborated based on the analysis of theory and insights, which will be tested during Stage 2 of the case study through interview questions.

\section{Stage 2}

When concluding the first stage, the obtained findings will allow a better understanding of the current and past situation along with theory from secondary research. The second stage will focus on value with the objective of understanding and interpreting the perceptions of the value of the stakeholders and their contexts. By conducting semi-structured interviews with a laddering technique, qualitative data will be collected.

A means-ends theory approach will be utilized to have an in-depth understanding of the stakeholders' perspective of value. This theory explains how people make certain choices to achieve desired goals or states (Gutman, 1982). This model is essentially linking value to behavior for which it is useful in the research to understand the value and further on evaluate 
the behavior. Boztepe's (2003) view on the means-end model suggests that the value is created in the connection between the properties of the product/service and the user. Based on that, it can be said that the user's perception of value occurs in a means-end way. This study will incorporate Boztepe's (2003) revisited the means-ends model in which she takes into account the situational and cultural factors. There is an opportunity to apply means-ends to understand the value and test the framework by considering the situational factors as the contexts of the producers and users.

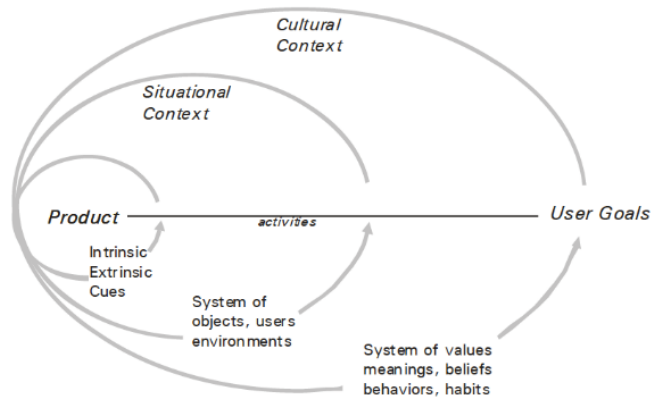

Figure 3: Revised means-ends model (Boztepe, 2003, p. 7)

The semi-structured interviews will be transcribed immediately after being conducted. Descriptive coding will be developed to summarize the information. These codes will be developed for organizational purposes from the interpretations to retrieve a deeper reflection on the data's meaning (Miles et al., 2013). Then, the development of additional codes will take place. Codes will be developed regarding the process to summarize the information and address the observable and conceptual actions in the data (Miles et al., 2013). The dramaturgical codes will be used to successfully comprehend the participants' experiences based on their objectives, conflicts, attitudes, emotions, and values (Miles et al., 2013). The transcripts revised with the codes allow for the development of themes to conclude the qualitative data findings.

Matrices will be used to display insights from qualitative data collection as a comparison tool between the producer and user contexts. There is a potential opportunity to utilize joumey mapping based on categorization for the interpretation of value if necessary when finalizing Stage 1 . For this, a visualization of the stakeholders' experiences from the different categories could be created.

\section{Potential Results}

Table 2: Objectives and Potential Results

\begin{tabular}{|c|c|}
\hline Objective & Potential Results \\
\hline $\begin{array}{l}\text { 1) Understand the user's perception of } \\
\text { value. } \\
\text { 2) Evaluate the impact of design by using } \\
\text { economic theory. }\end{array}$ & $\begin{array}{l}\text { - Develop conclusions on the case study as the } \\
\text { interpretations of the stakeholders' } \\
\text { perception of value. } \\
\text { - Develop an evaluation model that aims to help } \\
\text { organizations consider the perception of the } \\
\text { value of their users, their values and the } \\
\text { contexts. }\end{array}$ \\
\hline $\begin{array}{l}\text { 3) Analyze the relationship between design } \\
\text { and economics in order to contribute to the } \\
\text { business of design. }\end{array}$ & $\begin{array}{l}\text { Evaluate and conclude on the impact or worth of } \\
\text { design in (1) the process of understanding the } \\
\text { user, (2) the impact of those findings on the } \\
\text { decision-making process of the organization, and } \\
\text { (3) during the proposed evaluation. }\end{array}$ \\
\hline
\end{tabular}


Current paper is written from a pragmatic perspective that aims to develop an evaluation model to understand the user's perception of value based on economic theory. In this research, evaluating allows for 'an expression of judgment that enables a critical process of learning and changes ' (Foglieni, 2018, p. 72). There is an opportunity to incorporate evaluation as a step for decision-making in the value creation process. Therefore, the purpose is to guide organizations towards the creation of products, services or systems with a better understanding and a more measured perception of value. This potential model aims to demonstrate the economic value transcending and acknowledging the user's perception of value as its source. The potential outcomes of this research are linked with the established objectives that can be visualized in the above table.

\section{Acknowledgements}

I gratefully thank Dr. Hilary Collins who encouraged and supported my research throughout my journey studying design management.

\section{References}

- Becker, G. S. (2013). The economic approach to human behavior. University of Chicago press.

- Boztepe, S. (2003, October). The notion of value and design. In Journal of the Asian Design International Conference (Vol. 1).

- Boztepe, S. (2007). User Value: Competing Theories and Models. International Journal Of Design, 1(2), 55-63

- Butz Jr, H. E., \& Goodstein, L. D. (1996). Measuring customer value: gaining the strategic advantage. Organizational dynamics, 24(3), 63-77 Crossref

- Collins, H. (2010). Creative research: The theory and practice of research for the creative industries. La Vergne, TN;Lausanne;: AVA Academia.

- Cooper, R., Bruce, M., Wootton, A., Hands, D., \& Daly, L. (2003). Managing design in the extended enterprise. Building Research \& Information, 31(5), 367-378 Crossref

- Foglieni, F., Villari, B., \& Maffei, S. (2018). Designing better services: a strategic approach from design to evaluation. Cham, Switzerland: Springer. Crossref

- Gutman, J. (1982). A means-end chain model based on consumer categorization processes. The Journal of Marketing, 60-72. Crossref

- Heskett, J. (2008). Creating economic value by design. International Journal of Design, $3(1), 71-84$

- Heskett, J. (2017). Design and the creation of value. London: Bloomsbury Academic, an imprint of Bloomsbury Publishing Plc. Crossref

- Lockwood, T. (2007). Design value: A framework for measurement. Design Management Review, 18(4), 90-97.15 Crossref

- Menger, C. (1871). Principles of economics, trans. by James Dingwall \& Bert F. Hoselitz. Institute for Humane Studies. [RAM].

- Miles, M. B., Huberman, A. M., \& Saldana, J. (2013). Qualitative data analysis. Sage.

- Reichheld, F. F. (2015, July 16). The One Number You Need to Grow. Retrieved March 12, 2018, from https://hbr.org/2003/12/the-one- number-you-need-to-grow

- Sánchez-Fernández, R., \& Iniesta-Bonillo, M. Á. (2006). Consumer perception of value: literature review and a new conceptual framew ork. Journal of Consumer Satisfaction, Dissatisfaction, and Complaining Behavior, 19, 40.

- Simon, H. A. (1996). The sciences of the artificial. MIT press.

- Smith, A., \& Seligman, E. R. (1970). The wealth of nations. London: Dent.

- Schwab, K. (2017). The Fourth Industrial Revolution: its meaning and how to respond. Logistics \& Transport Focus, 19(2), 40-41.

- Thaler, R. (1980). Toward a positive theory of consumer choice. Journal of Economic Behavior \& Organization, 1(1), 39-60 Crossref 
Economic Theory to Visualize the Value of Design: A Case Study on The User's Perception of Value Maria Cristina Morejon Alava

- Von Mises, L. (1996). Human action. A Treatise on Economics, 4. Walsh, V., Roy, R., \& Bruce, M. (1988). Competitive by design. Journal of

- Marketing Management, 4(2), 201-216. Wieser, F. V. (1891). The Austrian school and the theory of value. The

- Economic Journal, 1(1), 108-121.

- Woodruff, R. B. (1997). Customer value: The next source for competitive advantage. Journal of the Academy of Marketing Science, 25(2), 139-153. Crossref

- World Economic Forum. The Fourth Industrial Revolution, by Klaus Schwab. Retrieved March 14, 2018, from https://www.weforum.org/about/the-fourth-industrial-revolution- by-KlausSchwab. 